\title{
Comparison of the Effects of Using Tygon Tubing in Rocket Propulsion Ground Test Pressure Transducer Measurements
}

\author{
Rebecca A. Farr ${ }^{*}$ and John T. Wiley ${ }^{\dagger}$ \\ NASA Marshall Space Flight Center, Marshall Space Flight Center, AL 35812 \\ and \\ Patrick Vitarius ${ }^{\ddagger}$ \\ Freel Innovations, Huntsville, AL 35815
}

\begin{abstract}
This paper documents acoustics environments data collected during liquid oxygenethanol hot-fire rocket testing at NASA Marshall Space Flight Center in NovemberDecember 2003. The test program was conducted during development testing of the RS-88 development engine thrust chamber assembly in support of the Orbital Space Plane Crew Escape System Propulsion Program Pad Abort Demonstrator. In addition to induced environments analysis support, coincident data collected using other sensors and methods has allowed benchmarking of specific acoustics test measurement methodologies during propulsion tests. Qualitative effects on data characteristics caused by using tygon sense lines of various lengths in pressure transducer measurements is discussed here.
\end{abstract}

\section{Introduction}

$A \mathrm{~N}$ acoustic sense line consists of a long, narrow tube, typically of metal or plastic, of which one end is attached Ito a pressure transducer. The other end is mounted at a location where pressure data collection is required.

Hostile conditions during propulsion tests provide an impetus to commonly employ sense lines in rocket engine ground testing. A thick metal sense line may survive temperatures and pressures that would damage or destroy an unprotected transducer. Alternatively, a sacrificial sense line designed to be partially or totally destroyed during each test can be easily replaced without risking damage to the more expensive pressure transducer itself.

Another advantage of the employment of sense lines is that they can simplify the physical arrangement of measurement devices at the test stand. The electronic pressure transducers may thereby be located in a centralized location, sharing a single power supply, housing, and data link.

Despite the widespread use of sense lines, their effects on data quality are often overlooked. It is a fundamental truth that, by virtue of the geometry of the sense line itself, linear transform theory states that the time domain pressure wave arriving at the pressure transducer will be significantly different than the pressure wave entering the open end of the sense line. Like any component of a data collection system, the sense line has an effect on the original signal that must be taken into account and modeled by a linear transfer function when analyzing the raw data.

In a previous study, the transfer function for commonly employed sense line configurations was determined and the limits of this model, especially the frequency range over which this model may be relied upon to produce reliably corrected data, were discussed.[12] This paper applies the model described in the previous research to two sets of hot-fire propulsion test data collected at Marshall Space Flight Center's (MSFC's) Test Laboratory in 2003 and 2004.

\footnotetext{
* Propulsion Test Engineer, Test Laboratory, Propulsion and Fluid Systems Test Division, ET12, Engineering Directorate.

${ }^{\dagger}$ Measurement Systems Engineer, Advanced Sensors \& Health Management Branch, EV23, Spacecraft and Vehicle Systems Department.

$\ddagger$ Associate Engineer, P. O. Box 12909.
} 


\section{Two Real World Rocket Test Data Sets}

The dynamic pressure data measured with PCB 112A22 pressure transducers using tygon sense lines presented here were collected in similar test setups during two different rocket hot-fire tests. The first set of data was collected in December 2003 during testing of the 40,000-lb-thrust, liquid oxygen (lox)-ethanol Rocketdyne RS-88 Orbital Space Plane (OSP) Pad Abort Demonstrator (PAD) liquid rocket engine thrust chamber assembly (TCA). The second set of data was collected in September 2004 during the firing of the 20,127-lbf, maximum sea level thrust, Thiokol nozzle configuration 5 (NC-5) 24-in solid rocket test motor (SRTM).

Boeing Rocketdyne Propulsion and Power Division was subcontracted by Lockheed Martin to provide the OSP PAD propulsion system. The design selected was based on the 60-klbf BANTAM engine, originally designed as a backup to NASA's Fastrac engine. The BANTAM baffled injector was a derivative of the injector developed by Rocketdyne as an upgrade to the ATLAS sustainer engine. Originally designed for lox/RP-1, the BANTAM TCA was adapted to use lox/ethanol in order to meet Crew Escape System Propulsion (CESP) requirements, and designated RS-88.

Lockheed Martin and the OSP Project Office specifically requested that acoustics and heating measurements be added to this Rocketdyne propulsion test program so that the PAD project could understand any induced environments that would potentially be created by the cluster of four RS- 88 engines envisioned for the demonstrator vehicle.

The OSP PAD tests were conducted in the 40-klbf test position at Test Stand 116 in the East Test Area of MSFC from November 21 to December 11, 2003. This test program is described in more detail in AIAA-2005-4422.[13] The OSP PAD acoustics environments data collection array geometry is shown in Fig. 1. Figures 2 and 3 show position 2 in more detail. Pressure transducer data presented here were collected at this location. One transducer was exposed to the direct environment, whereas the other one was attached to approximately 36 in of tygon sense line and located at the bottom of the post.

Acoustics environments data using similar sensors, methods, and array geometry were also collected in support of real-time radiography (RTR) operations conducted during the ATK Thiokol NC-5 24-in horizontal SRTM firing at the Solid Propulsion Test Article (SPTA) test stand at MSFC on September 2, 2004.

In this test, the RTR was employed in order to better understand ply-lift conditions that have been occurring in this particular composite nozzle design. It was hoped the RTR system would capture real-time images of the ply lift as it happened during the burn.

However, RTR had never been attempted on a 24-in SRTM and the acoustics environment had never been measured for this particular motor, so there was uncertainty regarding the expected performance of the RTR system during the hot-fire test. Some predictions based on extrapolations from other motor firings indicated the RTR equipment would have to endure an extremely harsh ignition shock and acoustics environment during the test. [15]

Therefore, in addition to the usual suite of instruments typically used on an SRTM, such as thermocouples, nozzle and combustion chamber pressure transducers, and resistance temperature devices, requirements were written to capture the

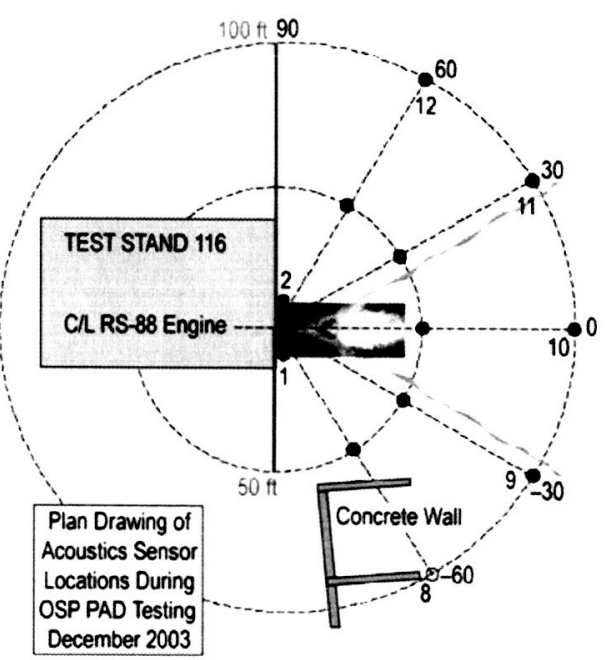
sound pressure levels occurring near the NC-5 motor during the firing. If the RTR system indeed failed to function during the firing, these acoustics data could be used later to better understand why it failed to capture images and to also develop countermeasures that will increase probability of successfully capturing real-time ply-lift images in future SRTM test firings. 


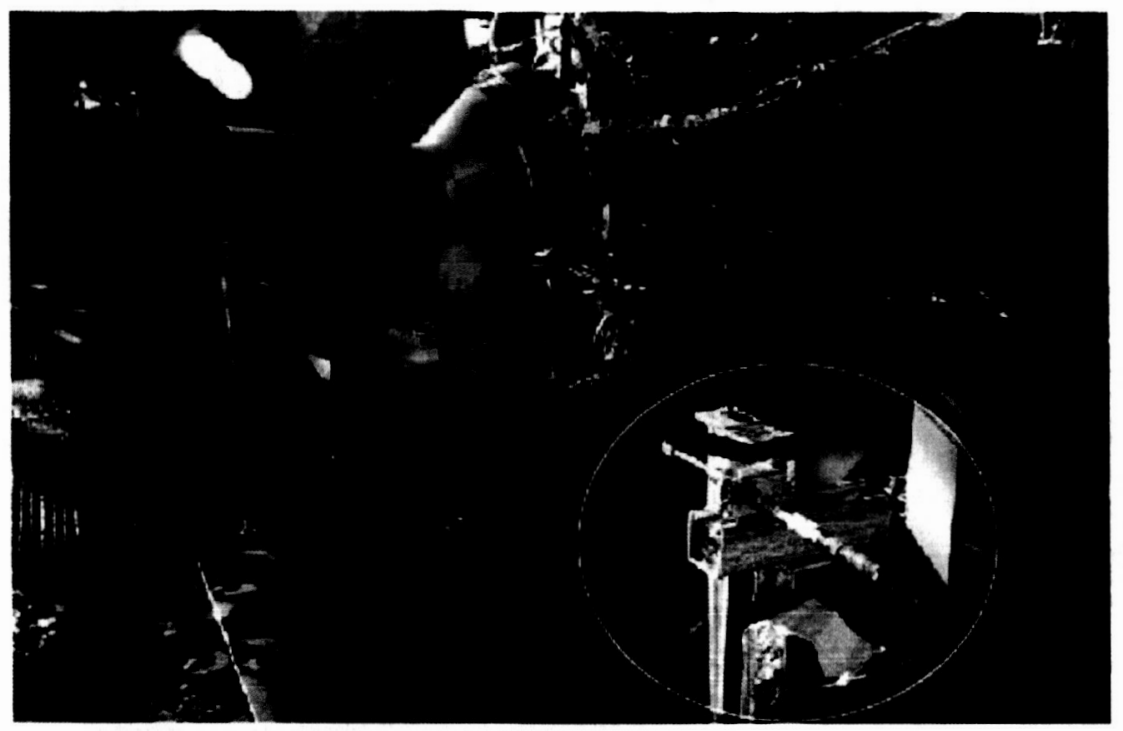

Figure 2. OSP PAD data collection position 2, showing sensors' location relative to the nozzle.

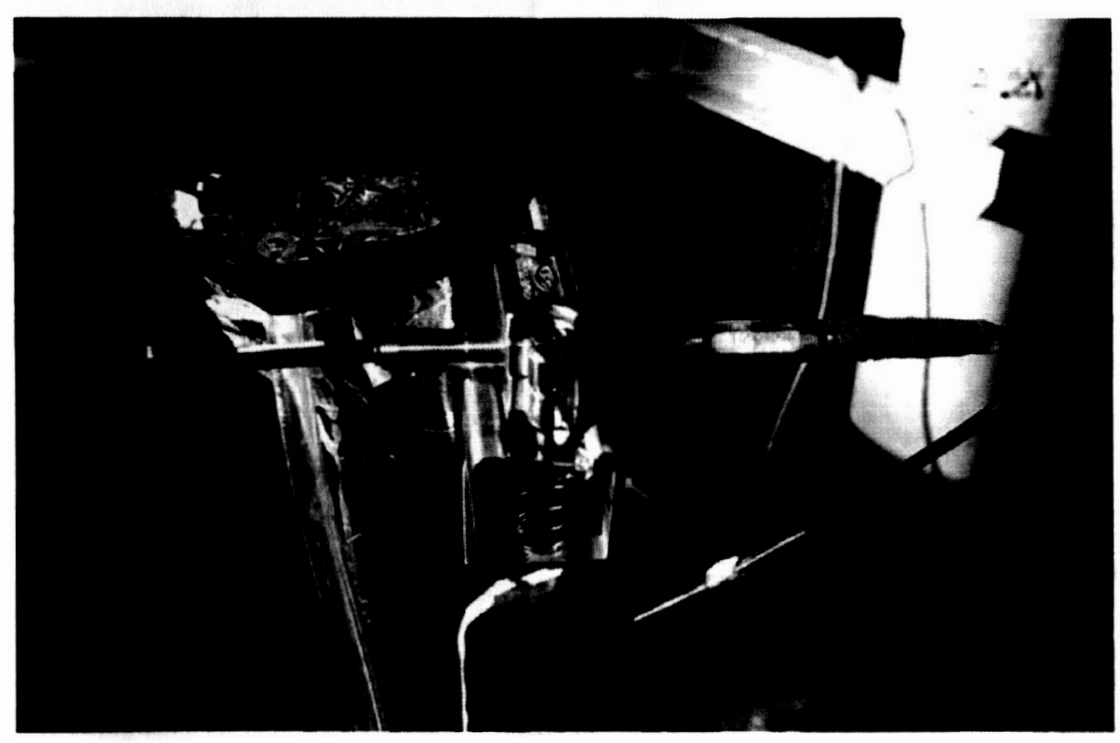

Figure 3. Sensors located at OSP PAD position $2,5 \mathrm{ft}$ from the nozzle: Larsen Davis microphone, PCB 112A22 pressure transducer, also tygon tubing to PCB transducer lower in post.

In this test, an acoustics array similar to the December 2003 OSP PAD testing was again employed, as shown in Fig. 4. The SRTM pressure transducer data presented here were collected at position 1, where four PCB $112 \mathrm{~A} 22$ pressure transducer sensors were co-located at the same location near the nozzle to support this comparative study on the effects of using various lengths of tygon tubing in pressure transducer measurements. These instruments were identical, but one was openly exposed while the other three were located at the end of 2-, 3-, and 4-ft lengths of tygon tubing. Figure 5 shows position 1 relative to the SRTM test article and Fig. 6 shows a closeup of the tygon tubing arrangement in that location. 


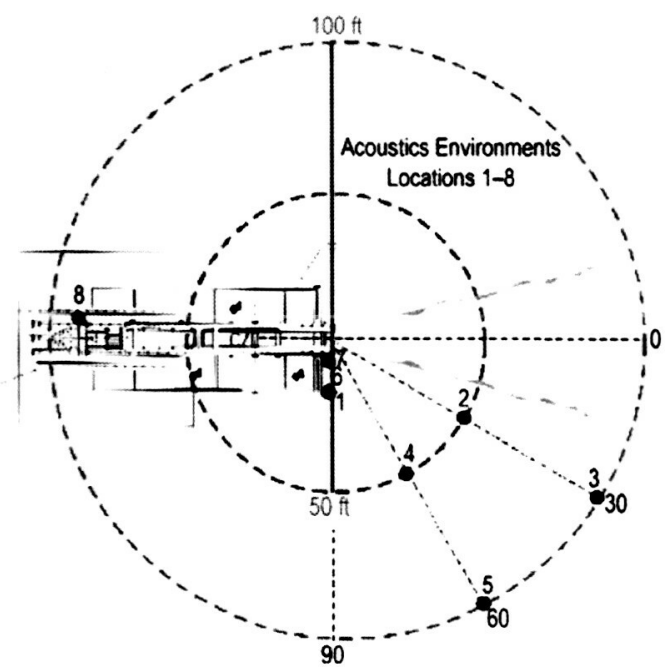

Figure 4. Acoustics environments data collection array used during SRTM NC-5 test, September 2004.

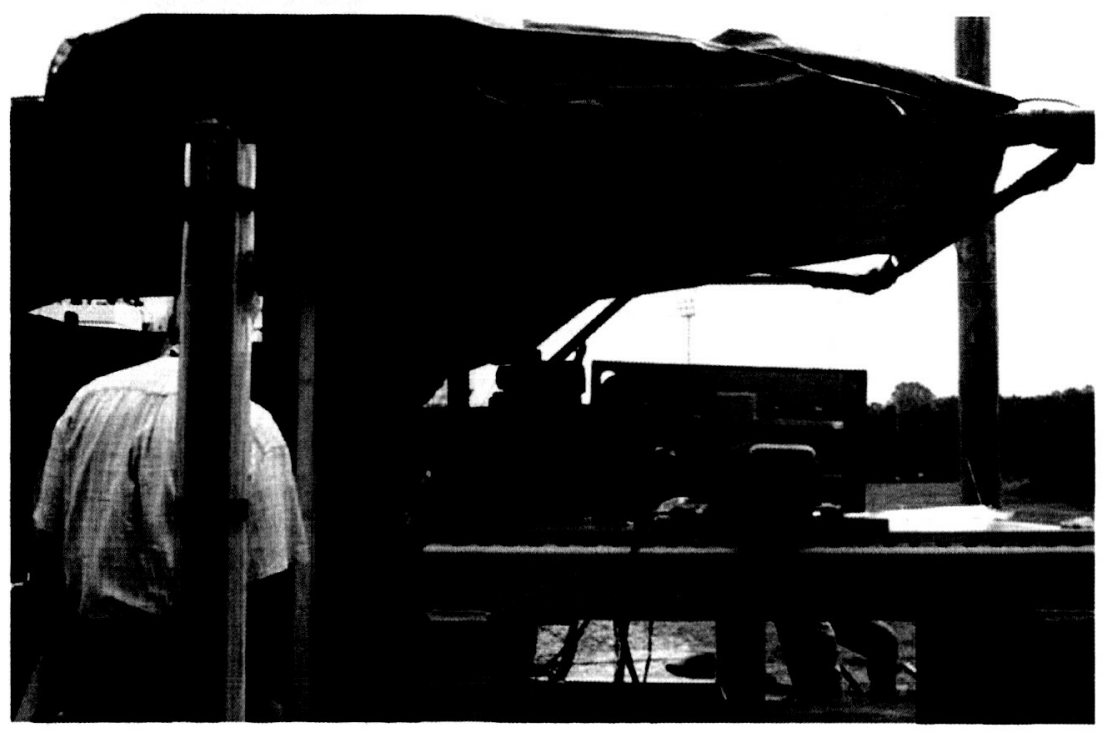

Figure 5. SRTM NC-5 data collection position 1, showing sensors' location relative to the nozzle (just past blue flange). 


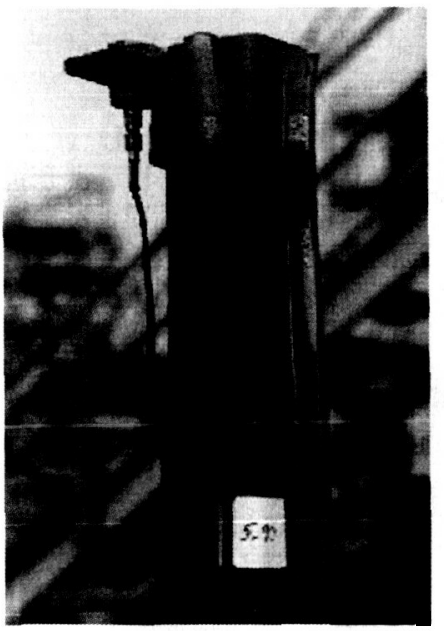

Figure 6. Sensors located at SRTM NC-5 position $1,5 \mathrm{ft}$ from the nozzle: PCB $112 \mathrm{~A} 22$ pressure transducer and tygon tubing to three other PCB transducers lower in post.

\section{Discussion and Results}

Figures 7 and 8 show raw pressure transducer time domain data from these two tests. These data are from exposed transducers of the same type that were not connected to tygon tubing sense lines. Figure 7 shows data collected $100 \mathrm{ft}$ from the OSP PAD nozzle, while Fig. 8 shows data collected $<10 \mathrm{ft}$ from the SRTM nozzle. These data immediately show some significant differences in liquid versus solid rocket noise environments typical during firing, especially in ignition start and end transients.

Examination of a plot of data from all four pressure transducers located at position 1 on the SRTM test shortly after ignition (Fig. 9) shows stark differences in the data characteristics which must be attributed to the sense line effects, since all other conditions were equal. Similar results are seen in examination of the coincident data from position 2 of the OSP PAD test.

The time domain plot in Fig. 10 from the OSP test shows some of the effects of sense lines on dynamic pressure measurements in more detail. The PCB transducer placed inside the sense line has a much less rapidly changing signal; this corresponds to a loss of high-frequency components in its power spectrum. In addition to this effect, it can be seen that the peaks and troughs do not line up but tend to lag behind the unprotected sensor. This time delay has been precisely measured in the instance of easily recognizable cutoffs and impulsive pressure events and found to correspond to the delay time introduced by speed-of-sound propagation down the length of the sense line. In addition to validating the linear approximation that the initial and final signals are similar enough for a multiplicative transfer function to be valid, this confirms that the primary mode of propagation is down the air column, and not within the walls of the tube.

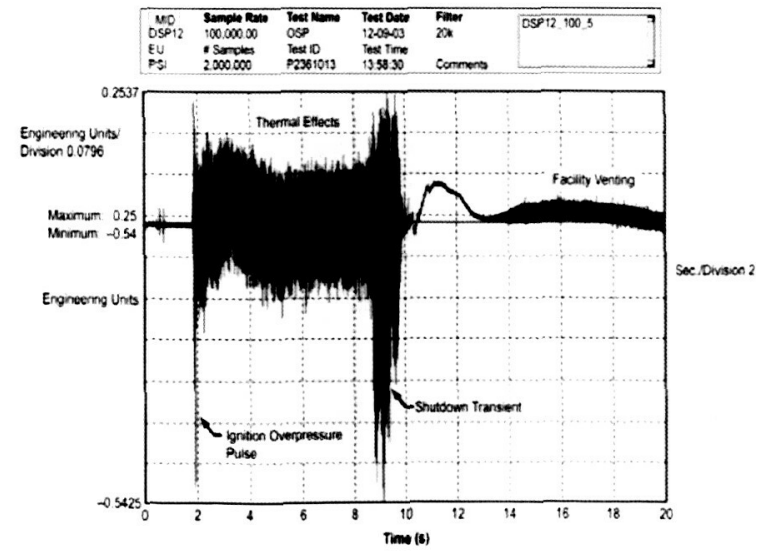

Figure 7. Graphical representation of pressure transducer data collected at location 12 during test 013, showing ignition overpressure pulse, thermal effects, shutdown transient, and posttest facility purge.

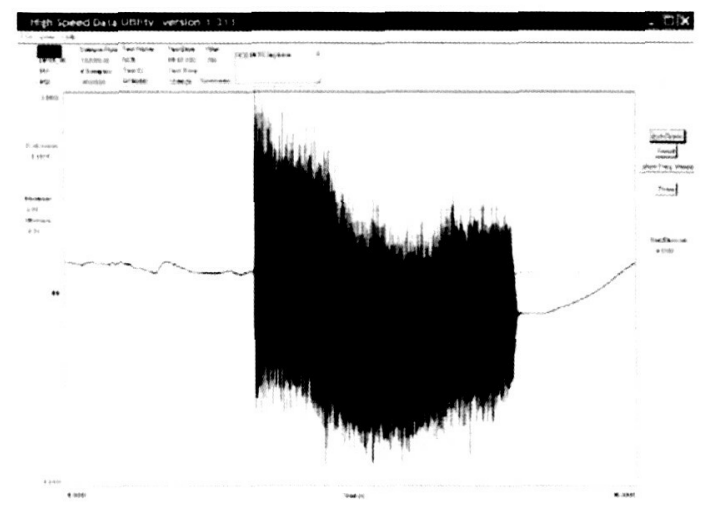

Figure 8. Pressure transducer data from position 1, SRTM test. (Bias is caused by radiative heating thermal effects of the SRTM plume on the sensor.) 


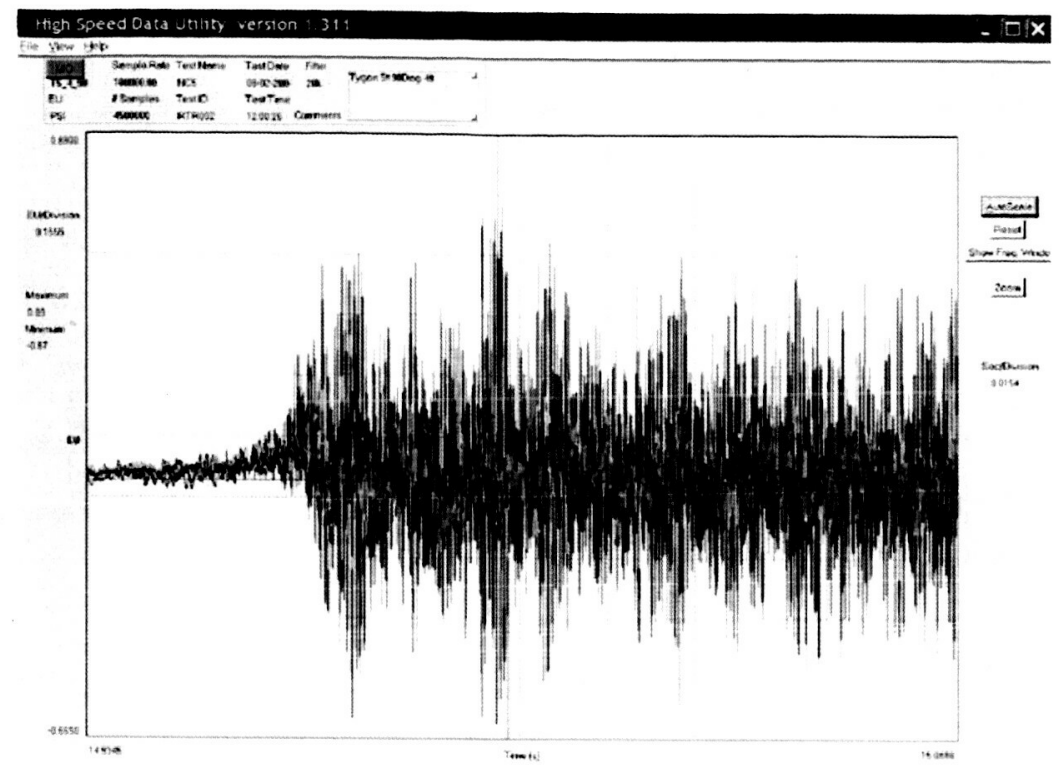

Figure 9. Data collected at SRTM test position 1 in the first second after ignition by the four PCB $112 \mathrm{~A} 22$ pressure transducers co-located on the same post.

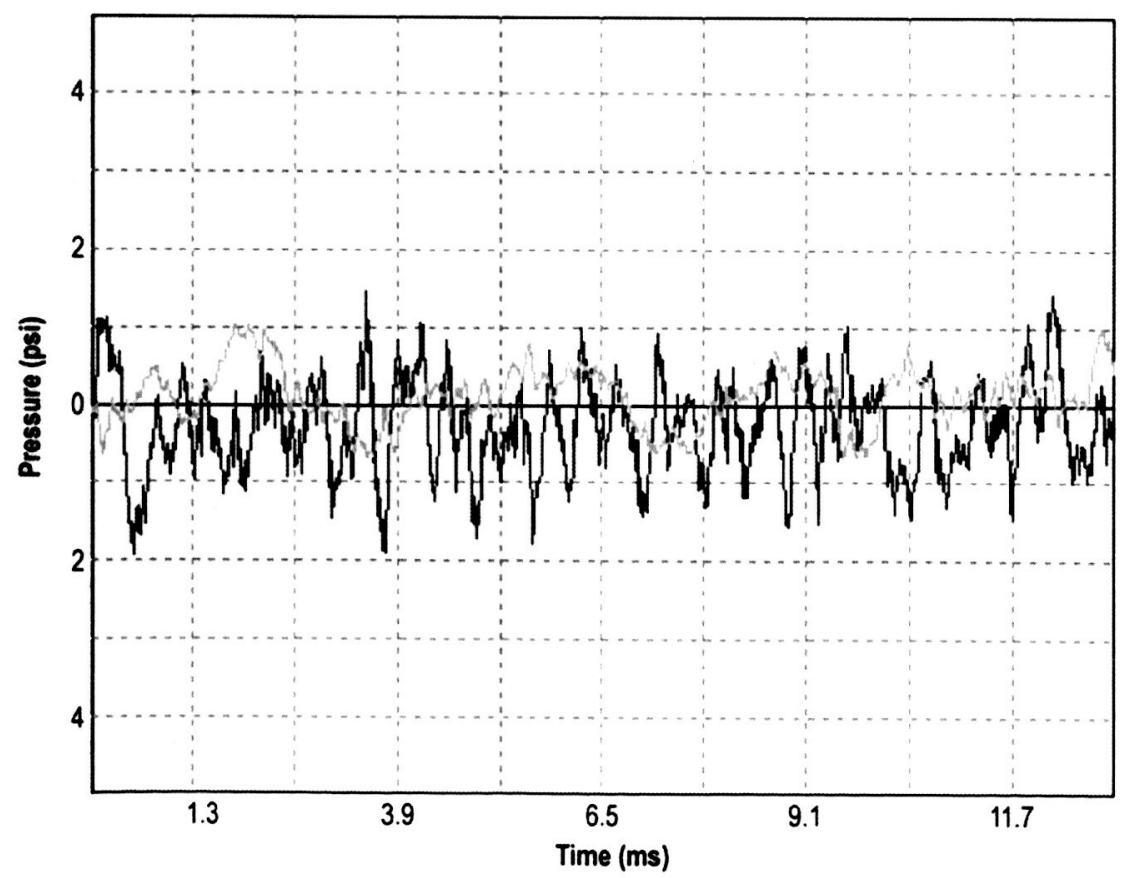

Figure 10. The time domain pressure signals of the PCB's placed alongside (dark) and at the end of (grey) the sense line for the OSP test firing. 
When examined in the frequency domain, the most apparent difference between the Fourier spectra of data from sensors placed with and without sense lines is the appearance of periodic resonant peaks. A preliminary analysis of the OSP PAD data shows that the centers of these resonant peaks are roughly consistent with the predicted frequencies for an air-filled tube open on one end and having a length of $36 \mathrm{in.}$ The predicted frequencies are 94 , $282,470,658$, and $846 \mathrm{~Hz}$. It can also be seen that while the unprotected sensor generally demonstrates a higher amplitude at higher frequencies in this range, the sense line sensor has higher amplitudes at the lower frequencies, especially around the second peak. This confirms that the signal has been altered by the sense line and that the primary effects are resonance and attenuation (Figs. 11 and 12).

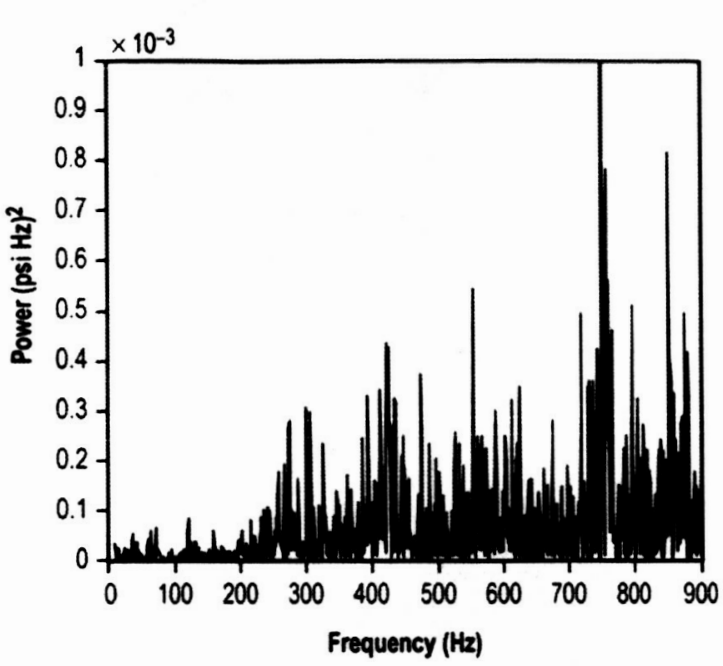

Figure 11. The power spectrum of the PCB placed alongside the sense line (OSP test).

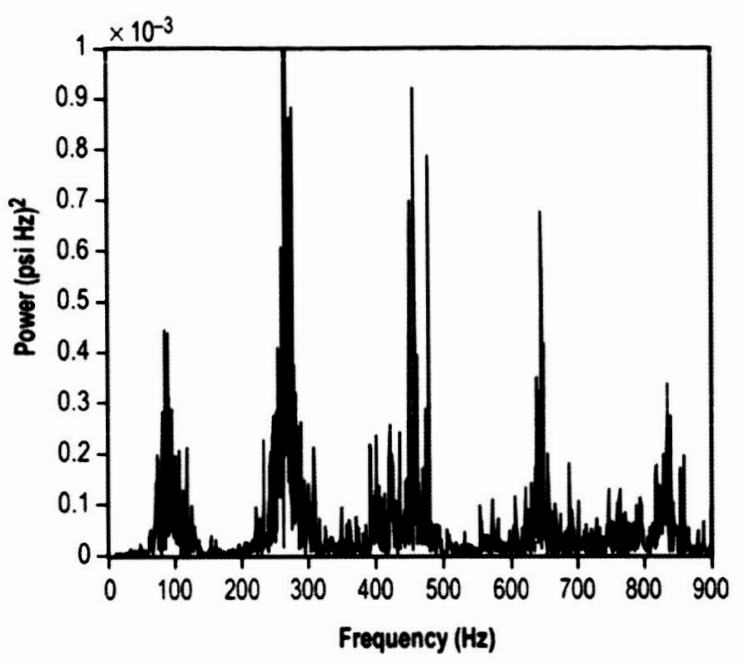

Figure 12. The power spectrum of the PCB inserted in the sense line (OSP test).

One of the authors has developed a simple method for partially correcting the sense line data [12]. In this method, a multiplicative amplitude transfer function is obtained by taking the average of the ratios of several sense line output spectra to their corresponding input spectra. The transfer function may be obtained for a sense line of arbitrary length, and a first-order approximation for other lengths may be obtained by simple scaling. The equation for the amplitude-only transfer function, expressed in terms of the first resonant frequency of the sense line, $f_{1}$, is

$$
H_{f i t}(f)=O(f) E(f)
$$

where

$$
O(f)=\frac{1}{600}\left[\begin{array}{l}
230-170 \cos \left(\frac{\pi f}{f_{1}}\right)+67 \cos \left(\frac{2 \pi f}{f_{1}}\right)-48 \cos \left(\frac{3 \pi f}{f_{1}}\right) \\
+37 \cos \left(\frac{4 \pi f}{f_{1}}\right)-21 \cos \left(\frac{5 \pi f}{f_{1}}\right)
\end{array}\right]
$$

and

$$
E(f)=5.5+11.5 e^{-\frac{f}{2.47 f_{1}}}
$$

When this method is applied to the sense line data, the result shown in Fig. 13 is obtained. 


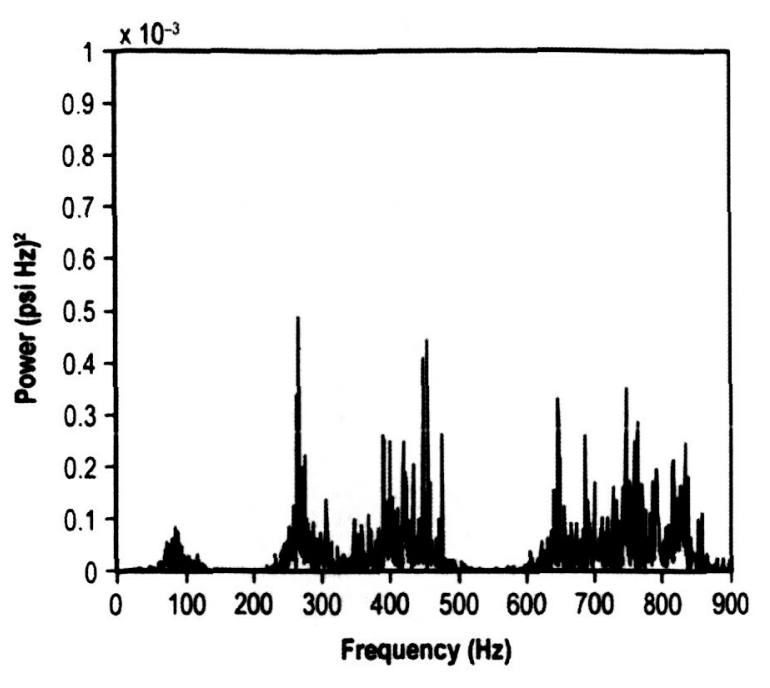

Figure 13. Calculated power spectrum based on sense line data (OSP test).

While it is immediately apparent that this method does not undo the effects of the sense line on the data, it can be seen that the adjustment removes traits of the power spectrum in Fig. 12 that might be ascribed (incorrectly) to the input signal. The refined data are much less spectral and show a shift towards higher frequencies, whereas the unrefined data are unreal-istically weighted with lowfrequency components. One shortcoming of the method is that it is unable to recover data from the null regions where the spectrum was near zero; spectral components in these regions are lost in this method unless sense lines of multiple lengths are employed.

The dual position sensor array employed sense lines of three different lengths. Examination of the data from each sense line shows a signal dominated by resonance (Fig. 14). The input signal is a wide peak centered around 1500 $\mathrm{Hz}$ with very little power at other frequencies; neither of these characteristics can be seen in the uncorrected sense line data.

The corrected data shown in Fig. 14 represent a partial improvement on the uncorrected data. While the amplitude information is still highly inaccurate, much of the resonant behavior has successfully been removed. The signal is correctly shown to be strongest in the region of $1500 \mathrm{~Hz}$, although it is represented as much too weak and still concealed behind what remains of the resonant behavior.

One further refinement may be made by determining the lengths of the sense lines rather than using the stated lengths. Curvature in the sense lines may lead to an effective air column length somewhat less than the actual length. Additionally, errors in cutting the sense lines, coupling with the transducers, and measuring the resulting length may lead to inaccurate lengths being reported. The effective lengths may be determined by inspecting the centers of the resonant peaks readily identifiable in the uncorrected sense line data. The fundamental frequency may be determined by halving the mean interval between resonant frequencies:

$$
f_{1}=0.5 * \frac{\sum_{i=1}^{n}\left(f_{i+1}-f_{i}\right)}{n} .
$$


The fundamental frequencies calculated from the effective lengths determined from the sense line data are summarized in Table 1. The corrected data obtained using these frequencies are shown in Fig. 15.

Table 1. Fundamental frequencies calculated from the effective lengths.

\begin{tabular}{|c|c|c|}
\hline $\begin{array}{c}\text { Sense Line Length } \\
\text { (ft) }\end{array}$ & $\begin{array}{c}\text { Integer Length } \boldsymbol{f}_{\mathbf{1}} \\
\mathbf{( H z )}\end{array}$ & $\begin{array}{c}\text { Experimental } \boldsymbol{f}_{\mathbf{1}} \\
\mathbf{( H z )}\end{array}$ \\
\hline 2 & 141 & 138 \\
3 & 94 & 92 \\
4 & 70 & 73 \\
\hline
\end{tabular}

(a)

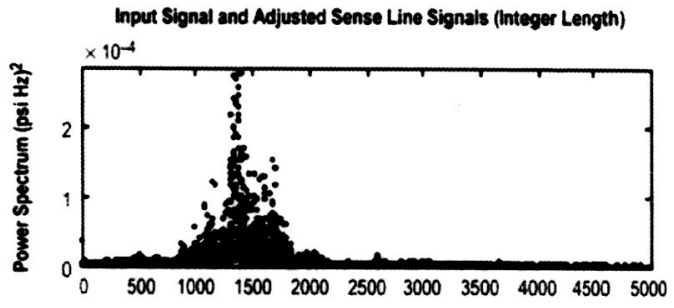

(b)

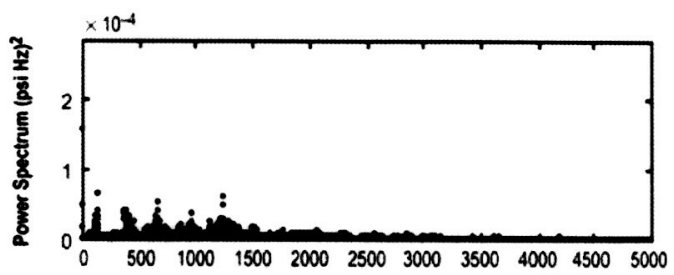

(c)

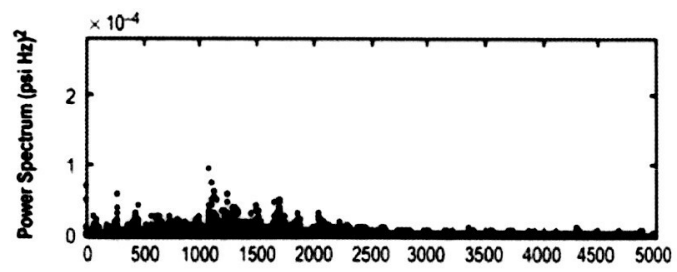

(d)

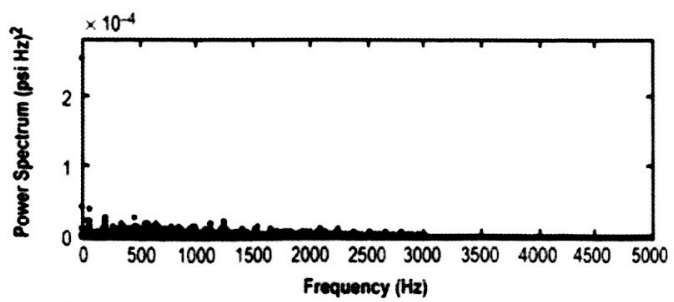

Figure 15. The power spectrum from the unprotected sensor and corrected spectra calculated using data from sense lines with various lengths: (a) openly exposed, (b) $2 \mathrm{ft}$, (c) 3 $\mathrm{ft}$, and (d) $4 \mathrm{ft}$. The lengths were taken to be exact (SRTM test).
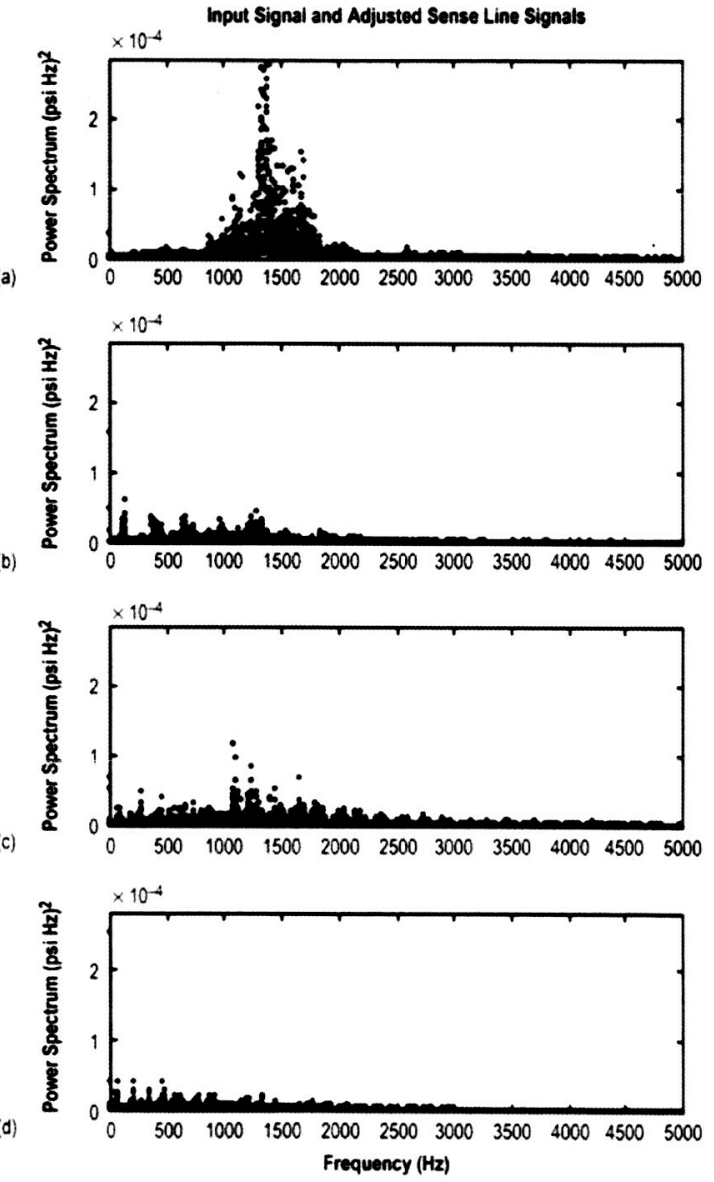

Figure 16. The power spectrum from the unprotected sensor and corrected spectra calculated using data from sense lines with various lengths: (a) openly exposed, (b) $2 \mathrm{ft}$, (c) $3 \mathrm{ft}$, and (d) $4 \mathrm{ft}$. Effective fundamental frequencies were calculated from inspection of the sense line data (SRTM test). 


\section{Conclusions}

The research presented here and in a previous study has provided an increased understanding of the concepts of acoustic resonance and linear transform theory and their effects on rocket dynamic pressure data collected using sense lines.[11] In order to obtain accurate results, engineers must be aware of the effect sense lines have on the raw dynamic pressure data when processing and analyzing these data.

It is possible to characterize a sense line by employing a second sense line placed far enough from the test site that an additional pressure transducer can be placed at the open end of the sense line. From this doubly instrumented sense line, a transfer function valid for the particular spectral profile of the event being observed may be obtained. The transfer function thus obtained can be used to calculate the pressure signal at the open end of the first sense line, placed in the hostile region from which data are needed.

Using identical sense lines obviates the need to scale the calculated transfer function. Where sense lines of different lengths are used, it would be best to use sense lines having the same length-to-diameter ratio so that the resonant peaks would have the same shape.

Despite the widespread use of sense lines, their quantitative and qualitative effects on data quality are often overlooked. Data analysts must take these effects into account when making engineering conclusions based on data collected with sense lines.

Finally, given the frequency limitations of sense lines, there is much room for improvement in developing other methods for obtaining pressure data from hostile environments, such as rocket engine combustion chambers.

The fundamental assumption presented here, that every component of a system has-a measurable and characterizable effect on time domain signals that it transmits-is a powerful concept that, although not without limitations, provides a key for understanding many electrical and mechanical systems. The techniques utilized here have broad, general applications and have demonstrated their utility as implemented in these particular examples.

\section{References}

'Brigham, E. O., The Fast Fourier Transform and Its Applications, Prentice-Hall, Englewood Cliffs, NJ, 1988.

${ }^{2}$ Calkin, M. G., Lagrangian and Hamiltonian Mechanics, World Scientific, Hackensack, NJ, 1996.

${ }^{3}$ Chen, Y., Vibrations: Theoretical Methods, Addison-Wesley Publishing Co., Boston, MA, 1966.

${ }^{4}$ Crandall, S. H., and Mark, W. D., Random Vibrations, Academic Press, Inc., London, 1963.

${ }^{5}$ Crichton, D. G., Dowling A.P., Fflowcs Williams, J.E., Hechl, M.A., and Leppington, F.A., Modern Methods in Analytical Acoustics, Springer-Verlag Publishing Co., New York, 1992.

${ }^{6}$ Griffiths, D. J., Introduction to Electrodynamics, Pearson Education, Inc., Upper Saddle River, NJ, 1999.

${ }^{7}$ Gupta, S. C., Transform and State Variable Methods in Linear Systems, John Wiley and Sons, Inc., NY, 1966.

${ }^{8}$ Irwin, H. P. A. H., Cooper, K. R., and Girard, R., "Correction of Distortion Effects Caused by Tubing Systems in Measurements of Fluctuating Pressures," Journal of Wind Engineering and Industrial Aerodynamics, Vol. 5, 1979, pp. 93-107.

9“Acoustics Loads Generated by the Propulsion System," NASA SP 8072, June 1971.

${ }^{10}$ Surry, D., and Stathopoulos, T., "An Experimental Approach to the Economical Measurement of Spatially-Averaged Wind Loads," Journal of Industrial Aerodynamics, Vol. 2, No. 4, January 1978.

${ }^{11}$ Temkin, S., Elements of Acoustics, John Wiley and Sons, Inc., NY, 1981.

${ }^{12}$ Vitarius, P. J., "Acoustic Transfer Functions for Pressure Sense Lines," M.S. Thesis, Department of Physics, The University of Alabama in Huntsville, Huntsville, AL, 2005.

${ }^{13}$ Farr, R. A., and Sanders, T. M., "RS-88 Pad Abort Demonstrator Thrust Chamber Assembly Testing at NASA Marshall Space Flight Center, November-December 2003," AIAA-2005-4422, 41 st AIAA Joint Propulsion Conference Proceedings (to be published).

${ }^{14}$ Barber, J. R., Mechanical and Electrical Vibrations, John Wiley and Sons, Inc., NY, 1964.

${ }^{15}$ Eldred, K. M., “Acoustic Loads Generated by the Propulsion System," NASA SP-8072, June 1971. 